\title{
KEPEMIMPINAN PARTISIPATIF KEPALA SEKOLAH DAN KOMPETENSI GURU SERTA PENGARUHNYA TERHADAP MUTU PENDIDIKAN
}

\author{
Priyo Suponco \\ SMP N 1 Paguyangan, Jln.Ir.H. Juanda Km 3 Indramayu Jawa Barat Indonesia, \\ priyosupanco_pasca@unwir.ac.id
}

Received April 27, 2018, reviewed Juni 30, 2018, published September 30, 2018

Citation: Suponco, P. (2018). Kepemimpinan Partisipatif Kepala Sekolah dan Kompetensi Guru serta Pengaruhnya Terhadap Mutu Pendidikan. Edum Journal, Vol 1, No 2, Hal 90-95, September 2018. DOI: https://doi.org/10.31943/edumjournal.v1i2.476

\begin{abstract}
ABSTRAK
Pokok masalah yang diungkap dalam penelitian ini adalah seberapa besar pengaruh kepemimpinan partisipatif dan kompetensi guru terhadap mutu pendidikan baik secara parsial maupun secara bersama-sama. Metode penelitian yang digunakan adalah explanatory survey method, dengan teknik pengumpulan data angket skala lima kategori Likert, terhadap 65 orang guru. Hasil penelitian menunjukkan, bahwa: (1) Terdapat pengaruh yang positif dan signifikan kepemimpinan partisipatif terhadap mutu pendidikan. (2) Terdapat pengaruh yang positif dan signifikan kompetensi guru terhadap mutu pendidikan. (3) Terdapat pengaruh yang positif dan signifikan kepemimpinan partisipatif dan kompetensi guru secara bersama-sama terhadap mutu pendidikan. Dalam rangka meningkatkan mutu pendidikan pada SMA Negeri, para guru perlu memperhatikan masalah penguasaan kompetensinya agar diperoleh efektivitas proses pembelajaran yang lebih optimal. Mutu pendidikan pada SMA Negeri sudah cukup baik, namun demikian masih perlu ditingkatkan agar diperoleh kualitas pendidikan secara keseluruhan. Peningkatan kualitas pendidikan antara lain dapat dilakukan dengan cara mengembangkan kepemimpinan partisipatif dan kompetensi guru.
\end{abstract}

\section{Kata Kunci: $\quad$ Kepemimpinan Partisipatif, Kompetensi Guru, Mutu Pendidikan}

\begin{abstract}
The main problem revealed in this research is how much influence participatory leadership and teacher competence have on the quality of education both partially and jointly. The research method used is explanatory survey method, with questionnaire data collection techniques on a scale of five Likert categories, to 65 teachers. The results of the study show that: (1) There is a positive and significant influence of participatory leadership on the quality of education. (2) There is a positive and significant influence of teacher competence on the quality of education. (3) There is a positive and significant influence of participatory leadership and teacher competence together on the quality of education. In order to improve the quality of education in State High Schools, teachers need to pay attention to the issue of mastering their competencies in order to obtain the effectiveness of a more optimal learning process. The quality of education in public high schools is good enough, but it still needs to be improved in order to obtain the quality of education as a whole. Improving the quality of education can be done by developing participatory leadership and teacher competence.
\end{abstract}

Keywords: Participatory Leadership, Teacher Competence, Education Quality 


\section{PENDAHULUAN}

Pendidikan merupakan salah satu jalan perubahan kualitas hidup. Salah satu indaktor peningkatan kualitas pendidikan yakni adanya mutu pendidikan di semua jenjang sekolah. Pendidikan yang bermutu merupakan pendidikan yang mampu memenuhi harapan dan mampu memenuhi keinginkan dan kebutuhan masyarakat, untuk mewujutkan harapan masyarakat, sekolah dan guru harus mempunyai harapan yang tinggi terhadap siswa (Aziz, 2015).

Peningkatan mutu pendidikan merupakan suatu keharusan untuk memenuhi kebutuhan sekolah dan masyarakat (Putra dkk, 2017). Mutu pendidikan merupakan kemampuan sekolah dalam pengelolaan secara operasional dan efisien terhadap komponen-komponen yang berkaitan dengan sekolah sehingga menghasilkan nilai tambah terhadap komponen tersebut menurut norma/standar yang berlaku (Fadhil, 2017). Kehadiran sebuah lembaga pendidikan yang bermutu sangat diharapkan oleh semua pihak (Putra, dkk, 2017). Mukbulloh (2011) urgensi pengembangan mutu pendidikan dengan melihat pada kondisi realitas yang berkembang, tidak dapat ditunda lagi.
Mutu pendidikan yang baik harus didukung oleh sejumlah faktor, baik faktor intern maupun ekstern. Menurut Ansyar (2012), ada tiga faktor penentu kualitas atau mutu pendidikan, yaitu (a) orang (pendidik), (b) program (kurikulum) dan (c) institusi (pimpinan). Oleh karena itu, upaya pemenuhan dan perwujudan segenap standar pendidikan nasional idealnya harus didukung oleh personal (orang) yang berkualitas, dibarengi dengan program (kurikulum) yang baik serta institusi (pimpinan) yang efektif (Hidayati, 2015).

Salah satu faktor penting didalam meningkatkan mutu pendidikan yakni kemimpinaan partisipitif kepala sekolah dan kompetensi guru. Berkaitan dengan kepemimpinaan partisipatif, menurut Hasibuan (2013:170), kepemimpinan (leadership) merupakan "proses mempengaruhi orang lain untuk memahami dan setuju tentang apa yang akan dikerjakan dan bagaimana tugas itu dapat dilakukan secara efektif, dan proses memfasilitasi usaha individu dan kelompok untuk mencapai tujuan bersama". Kepemimpinan partisipatif adalah cara memimpin yang memungkinkan para bawahan turut serta dalam proses pengambilan keputusan (Basri, 2014: 26). 
Berdasarkan hasil penelitian tentang pengaruh kepemimpinaan partisipatif kepala sekolah terhadap mutu pendidikan (1) Nurman, dkk (2018) menyimpulkan bahwa terdapat pengaruh secara bersamasama kepemimpinan partisipatif kepala sekolah dan kompetensi guru terhadap mutu sekolah di SMP Negeri di Kecamatan Bumiayu Kabupaten Brebes. (2) Juniawati (2017) menyimpulkan kepemimpinan partisipatif dan supervisi kepala sekolah memiliki korelasi sedang signifikan dan berkontribusi sebesar $17,8 \%$ terhadap kinerja mengajar guru, sedangkan sisanya dipengaruhi oleh variabel lain.

Hal lain berkaitan dengan kompetensi guru. Kompetensi guru merupakan seperangkat pengetahuan, keterampilan, dan perilaku yang harus dimiliki, dihayati, dikuasai, dan diwujudkan oleh guru dalam melaksanakan tugas keprofesionalannya (Depdiknas, 2005). Kompetensi yang harus dimiliki oleh setiap guru berdasarkan Undang-undang Nomor 14 Tahun 2005 tentang Guru dan Dosen pasal 10 ayat 1 menyebutkan bahwa guru harus memiliki beberapa kompetensi, yaitu kompetensi pedagogik, kompetensi kepribadian, kompetensi sosial, dan kompetensi profesional yang diperoleh melalui pendidikan profesi” (UUGD, 2009:8).

Berdasarkan hal tersebut, penelitian ini membahas tentang kepemimpinan partisipatif dan kompetensi guru dan pengaruhnya terhadap mutu pendidikan.

\section{METODE PENELITIAN}

Sesuai dengan tujuan penelitian yang hendak dicapai, metode yang digunakan adalah explanatory survey method. Mengingat masalah yang diteliti adalah gejala sosial, maka gambaran yang diperoleh di samping menggunakan pendekatan analisis kuantitatif berdasarkan informasi statistik juga digunakan pendekatan analisis kualitatif yang didasarkan kepada interpretasi terhadap hasil-hasilnya. Penelitian ini dilaksanakan pada sekolah menengah atas (SMA) negeri di Wilayah Brebes Selatan Kabupaten Brebes. Populasinya adalah seluruh guru pada SMA negeri tersebut yang berjumlah 188 orang.

Berkaitan dengan ukuran populasi di atas, Arikunto (2002:120) mengungkapkan bahwa: "untuk sekedar ancar-ancar maka apabila subjeknya kurang dari 100 lebih baik dimabil semua sehingga penelitiannya merupakan penelitian populasi. Teknik 
pengambilan sampel diambil dari setiap sekolah secara acak proporsional. Yaitu, dari masing-masing sekolah diambil sekitar $35 \%$. Penentuan guru yang menjadi respoden diambil secara acak (simple random sampling).

Penulis menggunakan teknik pengumpulan data melalui studi literatur, dokumentasi dan angket yang telah diuji validitas dan reliabilitas. Data kemudian diolah dan dianalisis menggunakan teknik analisis deskriptif dan verifikatif. Adapun teknik analisis verifikatif yang digunakan adalah analisis korelasi, koefisien determinasi, analisis regresi dan uji signifikansi.

\section{HASIL PENELITIAN DAN PEMBAHASAN}

Berdasarkan uji statistik, diperoleh keterangan objektif bahwa ada pengaruh kepemimpinan partisipatif terhadap mutu pendidikan, yaitu sebesar 0,7396. Hasil analisis korelasi parsial yang dideskripsikan pengaruh kepemimpinan partisipatif kepala sekolah $\left(\mathrm{X}_{1}\right)$ terhadap mutu pendidikan $(\mathrm{Y})$, jika variabel kompetensi guru $\left(\mathrm{X}_{2}\right)$ dikontrol menghasilkan harga $r_{\mathrm{y} 1}=0,7396$ dan nilai hitung $\mathrm{t}=8,6539$, dengan nilai $\mathrm{t}_{\text {tabel }}$ pada $\alpha=0,05$ dan $\mathrm{dk}=62$ sebesar
2,2971. Hasil pengujian variabel kepemimpinan partisipatif $\left(\mathrm{X}_{1}\right)$ atas data variabel mutu pendidikan (Y) diketahui $\mathrm{F}$ hitung sebesar 8,1294 dan $F_{\text {tabel }}$ pada $\alpha=$ $0,05, \mathrm{dk}_{1}=1$ dan $\mathrm{dk}_{2}=63$ adalah $=3,9934$.

Artinya koefisien regresi signifikan atau kepemimpinan partisipatif $\left(\mathrm{X}_{1}\right)$ berpengaruh secara signifikan terhadap mutu pendidikan (Y) pada $\alpha=0.05$. Determinasi variabel kepemimpinan partisipatif $\left(\mathrm{X}_{1}\right)$ terhadap variabel mutu pendidikan (Y) sebagaimana hasil perhitungan adalah sebesar $54,71 \%$. Artinya mutu pendidikan dipengaruhi oleh kepemimpinan partisipatif sebesar $54,71 \%$. Sisanya sebesar $45,29 \%$ pengaruhi oleh faktor lain. Pengaruh kompetensi guru terhadap mutu pendidikan, yaitu sebesar 0,7233 .

Hasil analisis korelasi parsial yang dideskripsikan pengaruh kompetensi guru $\left(\mathrm{X}_{2}\right)$ terhadap mutu pendidikan (Y), jika variabel kepemimpinan partisipatif kepala sekolah $\left(\mathrm{X}_{1}\right)$ dikontrol menghasilkan harga $\mathrm{r}_{\mathrm{y} 2}=0,5223$ dan nilai hitung $\mathrm{t}=4,8224$, dengan nilai $\mathrm{t}_{\text {tabel }}$ pada $\alpha=0,05 \mathrm{dan} \mathrm{dk}=62$ sebesar 2,2971. Hal ini dapat diartikan walaupun variabel kepemimpinan partisipatif terhadap mutu pendidikan dikontrol, pengaruh kompetensi guru 
terhadap mutu pendidikan tetap di positif dan signifikan.

Hasil perhitungan uji hipotesis variabel kompetensi guru $\left(\mathrm{X}_{2}\right)$ atas data variabel mutu pendidikan (Y) diketahui $\mathrm{F}$ hitung sebesar 23,7185 dan $F_{\text {tabel }}$ pada $\alpha=0,05$, $\mathrm{dk}_{1}=1$ dan $\mathrm{dk}_{2}=63$ adalah $=3,9934$. Artinya koefisien regresi signifikan atau kompetensi guru $\left(\mathrm{X}_{2}\right)$ berpengaruh secara signifikan terhadap mutu pendidikan (Y) pada $\alpha=0.05$. Determinasi variabel kompetensi guru $\left(\mathrm{X}_{2}\right)$ terhadap variabel mutu pendidikan (Y) sebagaimana hasil perhitungan adalah sebesar $27,28 \%$. Artinya mutu pendidikan dipengaruhi oleh kompetensi guru sebesar 27,28\%. Sisanya sebesar $72,72 \%$. pengaruhi oleh faktor lain.

Pengaruh kepemimpinan partisipatif dan kompetensi guru secara bersama-sama (simultan) terhadap mutu pendidikan, yaitu sebesar 0,8550. Hasil perhitungan diperoleh persamaan regresi $\hat{Y}=41,38+0,28 \mathrm{X}_{1}+$ $0,56 \mathrm{X}_{2}$. Hasil pengujian variabel kepemimpinan partisipatif $\left(\mathrm{X}_{1}\right)$ dan kompetensi guru $\left(\mathrm{X}_{2}\right)$ atas data variabel mutu pendidikan (Y) diketahui $\mathrm{F}$ hitung sebesar 18,7020 dan $F_{\text {tabel }}$ pada $\alpha=0,05$, $\mathrm{dk}_{1}=1$ dan $\mathrm{dk}_{2}=62$ adalah $=3,1453$. Artinya koefisien regresi signifikan kepemimpinan partisipatif $\left(\mathrm{X}_{1}\right)$ dan kompetensi guru $\left(\mathrm{X}_{2}\right)$ berpengaruh secara signifikan terhadap mutu pendidikan (Y) pada $\alpha=0.05$. Determinasi variabel kepemimpinan partisipatif $\left(\mathrm{X}_{1}\right)$ dan variabel kompetensi guru $\left(\mathrm{X}_{2}\right)$ terhadap variabel mutu pendidikan (Y) sebagaimana hasil perhitungan adalah sebesar $73.11 \%$. Artinya mutu pendidikan dipengaruhi oleh kepemimpinan partisipatif dan kompetensi guru secara bersama-sama sebesar $73,11 \%$. Sisanya sebesar $26.89 \%$ dipengaruhi oleh faktor lain.

\section{KESIMPULAN}

Berdasarkan permasalahan yang telah dirumuskan serta hasil penelitian dan pembahasan, maka dapat dikemukakan beberapa kesimpulan sebagai berikut: Terdapat pengaruh yang positif dan signifikan kepemimpinan partisipatif terhadap mutu pendidikan sebesar 54,71\%. Artinya mutu pendidikan dipengaruhi oleh kepemimpinan partisipatif sebesar 54,71\%. Sisanya sebesar $45,29 \%$ pengaruhi oleh faktor lain. Terdapat pengaruh yang positif kompetensi guru terhadap mutu sebesar 27,28\%. Artinya mutu pendidikan dipengaruhi oleh kompetensi guru sebesar 27,28\%. Sisanya sebesar 72,72\%. pengaruhi oleh faktor lain.Terdapat 
pengaruh yang positif kepemimpinan partisipatif dan kompetensi guru secara simultan terhadap mutu pendidikan sebesar 73.11\%. Artinya mutu pendidikan dipengaruhi oleh kepemimpinan partisipatif dan kompetensi guru secara bersama-sama sebesar $73,11 \%$. Sisanya sebesar $26.89 \%$ pengaruhi oleh faktor lain.

\section{DAFTAR PUSTAKA}

Ansyar, M. (2012). Inovasi dan Implementasi Kurikulum. Lokakarya Penyempurnaan Kurikulum Fakultas Tarbiyah IAIN Imam Bonjol Padang, 10 November 2012 di Bukittinggi.

Basri, H. 2014. Kepemimpinan Kepala Sekolah. Bandung: Pustaka setia

Aziz, A. (2015). Peningkatan Mutu Pendidikan. Jurnal Studi Islam, Vol 10, No. 2 Hal 206-218, Desember 2015

Fadhli, M. (2017). Manajemen Peningkatan Mutu Pendidikan, TADBIR: Jurnal Studi Manajemen Pendidikan, Vol. 1, No. 02, Hal 215-240, 2017.
Hasibuan, M. (2013). Manajemen Dasar Pengertian dan Masalah. Jakarta: Gunung Agung.

Hidayati. (2015). Kepemimpinan dan Peningkatan Mutu Pendidikan, Jurnal Tarbiyah, Vol. 22, No. 1, Hal 48-65, Januari-Juni 2015

Mukbulloh, D. 2011. Manajemen Mutu Pendidikan Islam. PT. Raja Grafindo Persada, Jakarta.

Nurman, M. (2018). Pengaruh Kepemimpinan Partisipatif Kepala Sekolah dan Kompetensi Guru Terhadap Mutu Sekolah Smp Negeri di Kecamatan Bumiayu Kabupaten Brebes. JMP Universitas PGRI Semarang, Vol 7, No 3, Desember 2018.

Putra, R.S, dkk. (2017). Strategi Peningkatan Mutu Pendidikan Pada Sma Negeri 3 Meulaboh Kecamatan Johan Pahlawan Kabupaten Aceh Barat, Jurnal Magister Administrasi Pendidikan, Vol 5, No. 3, hal 161166, Agustus 2017.

Undang-undang Nomor 14 Tahun 2005 Tentang Guru dan Dosen 